\title{
Development of a tomato load/yield monitor
}

\author{
G. Pelletier ${ }^{a}$, Shrini K. Upadhyaya ${ }^{\text {b,* }}$ \\ ${ }^{a}$ Cotton Ginning and Production Laboratory, United States Department of Agriculture, Lubbock, \\ $T X, U S A$ \\ ${ }^{\mathrm{b}}$ Department of Biological and Agricultural Engineering, University of California, Davis, \\ CA 95616, USA
}

\begin{abstract}
The objective of this study was to develop a load/yield monitor for mounting on a processing tomato harvester. A continuous mass flow-ype yield-ensing device equipped with load cells and a vibration-resistant angle transducer along with a differential global positioning system (DGPS) was developed to collect spatially variable yield data in real-time. Both analog and digital signal processing were employed to maximise the accuracy of data acquisition. The yield monitoring system was calibrated, validated, and tested during the 1997 harvesting season. The coefficient of determination, $r^{2}$, between the actual fruit weight and the yield monitor prediction was 0.997 . The system was then used to measure yield variability and produce yield maps. There were significant spatial variations in processing tomato yield. The lowest $20 \%$ yielding area within a field produced less than half the tomatoes compared to the highest $20 \%$ yielding area within the same field. (c) 1999 Elsevier Science B.V. All rights reserved.
\end{abstract}

Keywords: Mass flow measurement; Precision farming; Processing tomatoes; Yield monitor

\section{Introduction}

A yield monitor is one of the key elements in a precision farming system. It provides a direct feedback to the farmer by quantifying the variability in yield within a field and raising questions regarding management practices. Yield monitors have become commercially available for grain, cotton, and potatoes, but most of the efforts in precision farming have focused on grain crops due to the availability of proven combine grain yield monitors (Sudduth et al., 1991). How-

\footnotetext{
* Corresponding author.
} 
ever, reliable yield monitors are currently not available for many of the specialty crops, such as processing tomatoes.

California grows about $93 \%$ of the processing tomatoes produced in the United States. It is one of the major crops grown in the Central valley region of California. In 1996 nearly 127 million hectares were planted to the processing tomatoes, resulting in 9.7 million tons of tomatoes worth 664 million dollars (California Statistical Abstracts, 1998). The yield varied from about $45 \mathrm{t} / \mathrm{ha}$ in heavy clay soils to about $90 \mathrm{t} / \mathrm{ha}$ in loamy soils. The state average yield was $76 \mathrm{t} / \mathrm{ha}$ in 1996. Processing tomato is an irrigated crop and is usually grown on a $1.52-\mathrm{m}$ bed with a plant spacing of approximately $0.3 \mathrm{~m}$. The harvesting operation is completely mechanized and there are approximately 300 frontline harvesters in use today. These harvesters work round the clock during the peak harvesting season (July and August). Typical harvesting speed is about $5 \mathrm{~km} / \mathrm{h}$ which results in a theoretical field capacity of about $0.76 \mathrm{ha} / \mathrm{h}$. Actual field capacity is about $0.5 \mathrm{ha} / \mathrm{h}$ or $38 \mathrm{t} / \mathrm{h}$. The average mass flow rate within the harvester is approximately $11 \mathrm{~kg} / \mathrm{s}$. The harvested crop is loaded on to a double-trailer truck which can carry about 22.7 tons of tomatoes per load.

The harvester is a self-propelled machine which cuts the plants just below the soil surface and pushes them onto a conveyor which feeds the plants to a vibratory shaker (Fig. 1). This primary conveyor separates soil and some clods from plant material. The shaker separates green and red tomatoes from the vine and drops them along with some plant material onto two cross conveyors. One of these cross conveyors moves about half the material to the right and other moves the rest to the left. These cross conveyors deposit materials onto two side conveyors, one on each side of the machine. As the material moves rearward on these side conveyors separation of red tomatoes from all other materials occurs. First, two suction fans

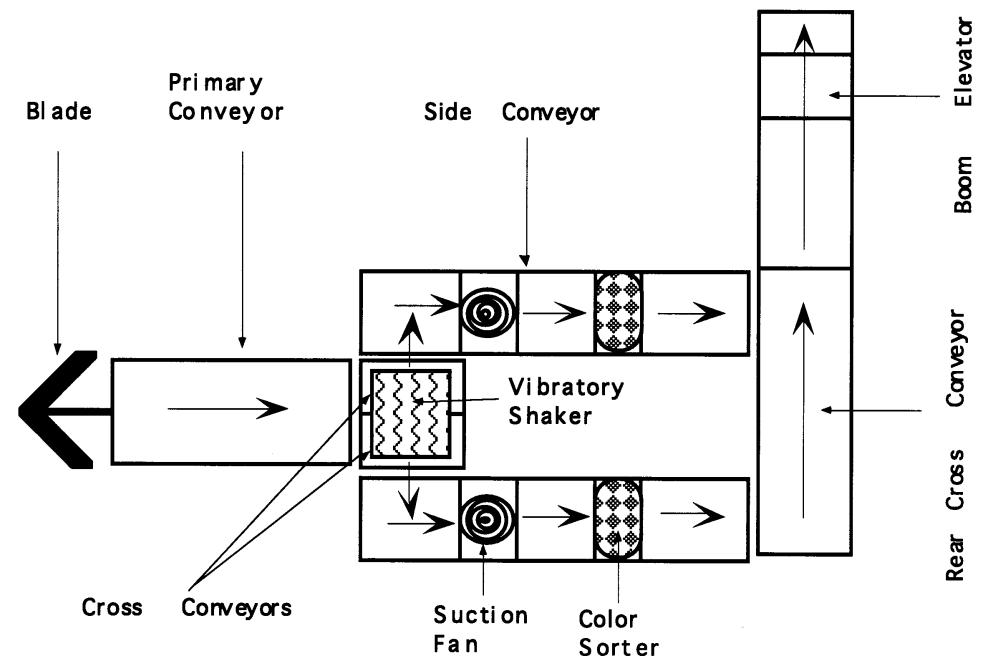

Fig. 1. A schematic diagram of the material flow through a tomato harvester. 
(one on each side) pick up leaves and vines and blow them to the rear of the machine. Next, electronic colour sorters detect red tomatoes and kick out all other materials, particularly green tomatoes. Finally, three or four farm workers on each side remove all unwanted materials (unsorted greens, clods, moldy tomatoes etc.). The two side conveyors deposit the mostly clean, red tomatoes on to a rear cross conveyor. Note that splitting the material that moves through the machine into two parts at the shaker and then rejoining them on the rear cross conveyor leads to a difference in path length to be traversed by the material that travel the right side conveyor compared to the material that traveled the left side conveyor. This path length difference is equal to the length of the rear cross conveyor. Depending on the harvesting condition (i.e. lot of molds), an additional crew may be employed to remove unwanted materials from the red tomatoes on the rear cross conveyor. The weight of these red tomatoes is the marketable yield for processing tomatoes. The rear cross conveyor deposits the red tomatoes onto a boom elevator, which lifts the tomatoes and deposits them in a truck.

Since there are approximately 300 tomato harvesters in use in California today and no more than 20 new ones are added annually, any yield monitoring system should preferably retrofit onto existing machines easily. In addition, the law requires that the total load including the truck weight must not exceed $36.3 \mathrm{t}$. Since the weight of trucks tend to vary in the range of $10.9-12.7 \mathrm{t}$, it is safe to limit the tomato load to within $23.6 \mathrm{t}$. Because of this law, producers are keen on knowing the exact truck load in order to avoid penalty. They prefer a truck load of $22.7 \mathrm{t}$ which provides a margin of error of $0.9 \mathrm{t}$ or about $4 \%$. The coupling of a DGPS to a load monitor provides the necessary information for producing a yield map.

The objective of the work described in this paper was to develop a processing tomato load/yield monitor that could easily be retrofitted onto the existing harvesters.

\section{Review of literature}

\subsection{Yield measurement}

Several methods have been developed over the years for the measurement of mass flow for yield monitoring. Vanischen and De Baerdemaeker (1993) developed a technique for measuring corn silage yield using torque transducers on the silage blower shaft and cutter-head drive shaft. They found that the system performed well when integrated over a $2500-\mathrm{kg}$ load of silage. Auernhammer et al. (1995) developed a radiometric yield measurement system for a forage harvester utilizing a radioactive source and detector (not currently legal for use in the USA for food). Wild et al. (1994) reported a hay yield monitoring system for round balers which used strain gages on the tongue and axle of the vehicle to provide a measure of the weight of the baler and the bale. Additionally, they 
included accelerometers to measure vertical accelerations during operation. When stationary, the monitor was able to determine the load within $2 \%$ of the actual weight. Measurements under dynamic conditions were still under investigation. An optical sensor has been developed by Wilkerson et al. (1994) for yield monitoring picker harvested cotton. The system used an array of lights and photo-detectors. Laboratory tests showed that an integrated measurement over an entire load correlated well with the actual load with a coefficient of determination of 0.93. Commercial grain monitors produced by AgLeader ${ }^{\circledR}$, Deere $\&$ Co ${ }^{\circledR}$, and Micro-Trak $^{\circledR}$ use an impact plate for yield monitoring, which sense the force produced from a change in the momentum in a small quantity of grain as it hits a pressure plate.

Campbell et al. (1994) described a system for potato yield monitoring. The system consisted of a single idler wheel (steel hub/rubber tire) instrumented with a load cell, one on each side of the conveyor chain. The load cells were used to measure the weight and a speed sensor was used to measure the conveyor speed. The conveyor in this case was set at a fixed angle. A similar system was described by Hofman et al. (1995) for measuring sugarbeet yield. Another system for potatoes was described by Rawlins et al. (1995), which used a pivoted table with a load cell at the free or non-pivoted end to measure tuber weight. Calibrations of the systems were performed by correlating the output of the yield monitor with the truck weights (approximately $23000 \mathrm{~kg}$ ). The weights from the yield monitor were associated with ground positions based upon DGPS measurements. A correction for the harvester transport lag from digging to weighing was performed by a simple time delay. Yield monitors for specialty crops such as peanuts and oranges are currently under development (Durrence et al., 1998; Miller and Whitney, 1998). There are currently no reliable yield monitors for crops such as processing tomatoes.

\subsection{Harvester dynamics}

Harvester dynamics is a major concern in yield monitoring. Nolan et al. (1996) used a simple technique for correcting the harvester lag by using both a simple time delay model and performing nearest-neighbour filtering on yield maps. Boydell et al. (1996) reported much better results for correcting the yield data by deconvoluting the dynamics of a peanut harvester, and then passing the data through a low pass filter to reduce the noise amplified through the deconvolution filter (high pass filter). Deconvolution is the mathematical process of obtaining the input signal to the system knowing the output signal and the transfer function of the system. Pierce et al. (1997) reported that a simple time delay model with smoothing produced better yield maps than more complicated models that describe the harvester dynamics as a first-order system and then deconvolute to obtain corrected yield data. This paper addresses the issues related to harvester dynamics and signal processing which are necessary to obtain reliable spatially variable yield data. 


\section{Design of the tomato yield monitor}

\subsection{General considerations}

Impact plates, optical volumetric measurements, radiometric techniques, and continuous weighing methods are some of the more commonly used methods for monitoring crop yield. For tomatoes, the coefficient of restitution is highly variable depending upon maturity. This would preclude the use of impact type of measurements. Similarly, due to the variability in the tomato density among various varieties, an optical volumetric measurement is also an unlikely method for providing the required accuracy. As stated before, the use of a radiometric or a $\mathrm{X}$-ray technique is not feasible in the United States for health and environmental reasons. This leaves only a few options: (i) bulk weighing/drop bucket; (ii) instrumenting the entire harvester for total weight; or (iii) the use of belt weighing techniques similar to the ones employed by Campbell et al. (1994) and Hofman et al. (1995) for potatoes and sweet potatoes. As the belt weighing option provides the easiest retrofit, we decided to pursue this technique.

\subsection{Location of the yield monitor}

Belt weighing in non-mobile applications is a very mature science. Colijn (1983) reported that errors in belt weighing could be limited to $0.25-0.5 \%$ provided that a number of fundamental criteria were followed in the use and installation of the weighers. These criteria were for stable, non-mobile platforms of long belt runs (over $30 \mathrm{~m}$ ) with a maximum of $12^{\circ}$ inclination. However, application of this technology to the tomato harvester presented many challenges. The most serious challenge was the operation of the belt weigher in a dynamic, off-road environment with a changing conveyor angle. A belt weighing system mounted on a tomato harvester is subjected to strong harmonic vibrations due to the mechanical shaker used to remove the fruit from the vine together with additional vibration from the conveyor, the engine, hydraulic motors, and random inputs from the uneven ground surface as the harvester is driven through the field. Moreover, several other factors related to data acquisition, recording, filtering, and aggregation of the final data to produce a useful and accurate yield map had to be considered.

As explained earlier red tomatoes are separated from other materials up until the point where the fruit is deposited in the truck. This made the last section of the boom elevator, right before the fruit is delivered to the truck, the ideal location for yield measurement (Figs. 1 and 2). Unfortunately, this is a poor location for the yield monitor location because this section of the boom elevator is only about $2 \mathrm{~m}$ in length and is rarely level. The inclination of this section averaged about $22^{\circ}$ from the horizontal and fluctuated by $\pm 30^{\circ}\left(-8\right.$ to $\left.+52^{\circ}\right)$ from this mean value. This situation made it necessary to incorporate an angle sensor to the yield monitoring system. The development of the yield monitor took place over a 3-year period. Our preliminary results indicated that a three-roller system which consisted of a weigh roller and a support idler on each side of this weigh idler was the preferred system 


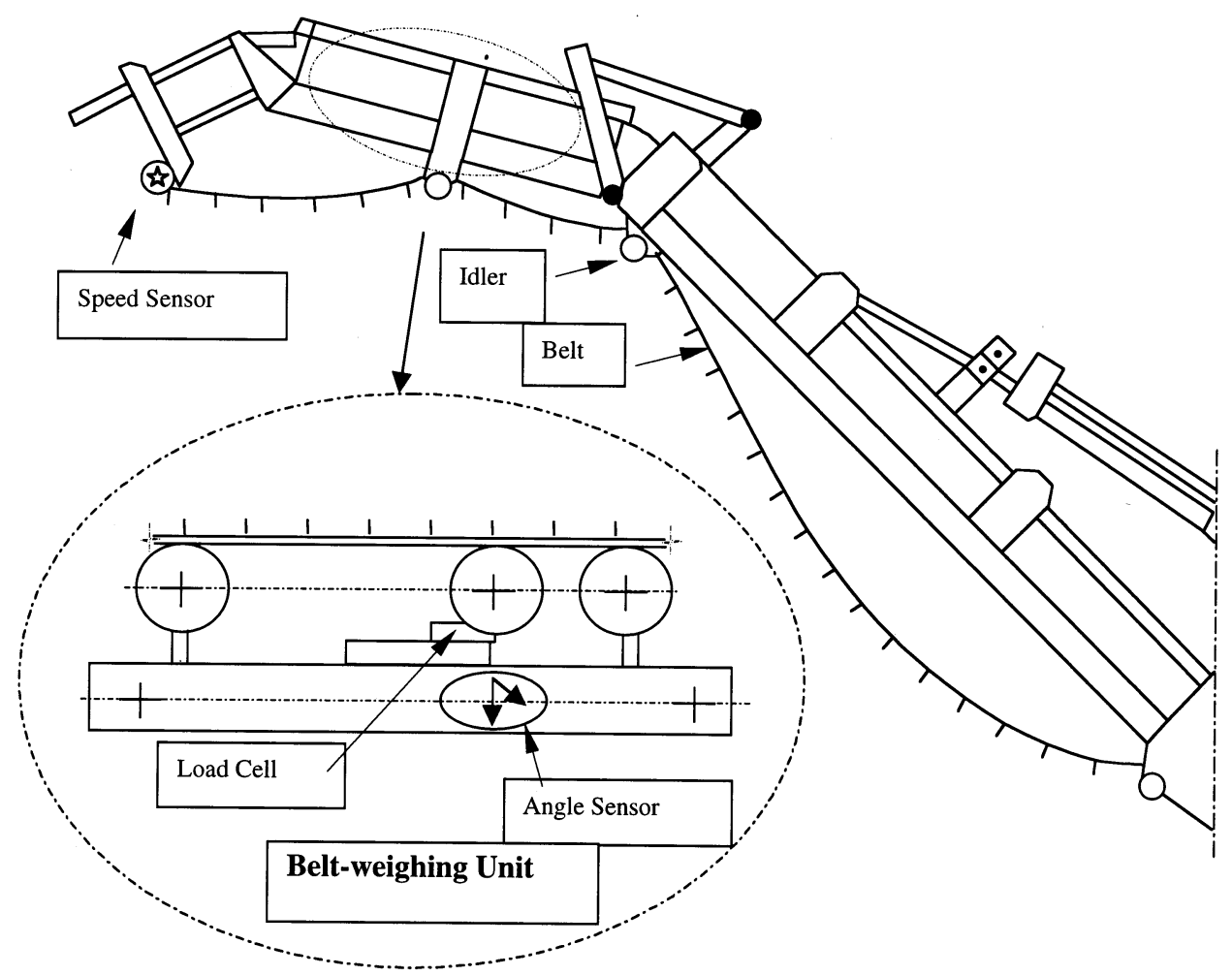

Fig. 2. A schematic diagram of a three-roller, continuous belt-weighing type load monitor mounted on the boom elevator of a tomato harvester.

compared to either a table type design or a single weigh roller design (Fig. 2). One of the key factors that determines the accuracy of the weight measurements was found to be the alignment between the weigh roller and the idler rollers. More accurate alignment of rollers helps minimize the effect of changing belt tension on the weight measurement.

Colijn (1983) reported that, although a conveyor belt is a flexible tension member, under tension the belt behaves like a beam. Analyzing the belt scale as a beam leads to a statically indeterminate system in which the load on the weigh roller not only depends on the active weigh region of the belt (the span between the two idler rollers), but it also depends on the loading on the belt outside the active weigh region. Pelletier (1998) analyzed this statically indeterminate system and showed that its amplitude response can be represented by Fig. 3. This figure shows that the load in the adjacent bay reduces the weight sensed by the weigh idler. This should not be a problem if it were consistent. But, any misalignment between idlers in the adjacent bay can introduce errors (Colijn, 1983). The ratio of the unloading caused by adjacent bays to the positive loading caused by the active bay is about $10 \%$. From the design point of view, this demonstrates the need for precise 
alignment between weigh idler, adjacent idlers, and idlers in adjacent bays. In this study the three-roller system shown in Fig. 2 along with an angle transducer was used to sense processing tomato yield in real-time. A low-frequency $(2.25 \mathrm{~Hz})$ simple pendulum and a single-chip accelerometer (Model: ADXL05, Analog Devices) were tested for use as an angle transducer. Although both these units worked well under field conditions ( $\pm 2 \%$ tolerance), the single-chip accelerometer was found to be much more compact, robust and easy to incorporate into the yield monitoring system.

\subsection{Spatial resolution}

In order to design a data acquisition and signal processing system, it was necessary to decide on the minimum possible spatial resolution. In spite of the progress made in plant breeding, two adjacent plants under identical soil and environmental conditions would still yield different amounts of tomatoes because of individual plant-to-plant variations. To overcome this problem, it is desirable to average the response of at least 30 plants $^{1}$. At a typical plant spacing of $0.3 \mathrm{~m}$, this translates to a distance of $9 \mathrm{~m}$ in the field. At a ground speed of $5 \mathrm{~km} / \mathrm{h}$, it would take $6.5 \mathrm{~s}$ for the harvester to travel $9 \mathrm{~m}$. From the Nyquist sampling theorem, the minimum sampling frequency to provide this spatial resolution rate is about $0.3 \mathrm{~Hz}$. Our objective was to design a signal processing system which would maintain acceptable accuracy of the data up to this frequency.

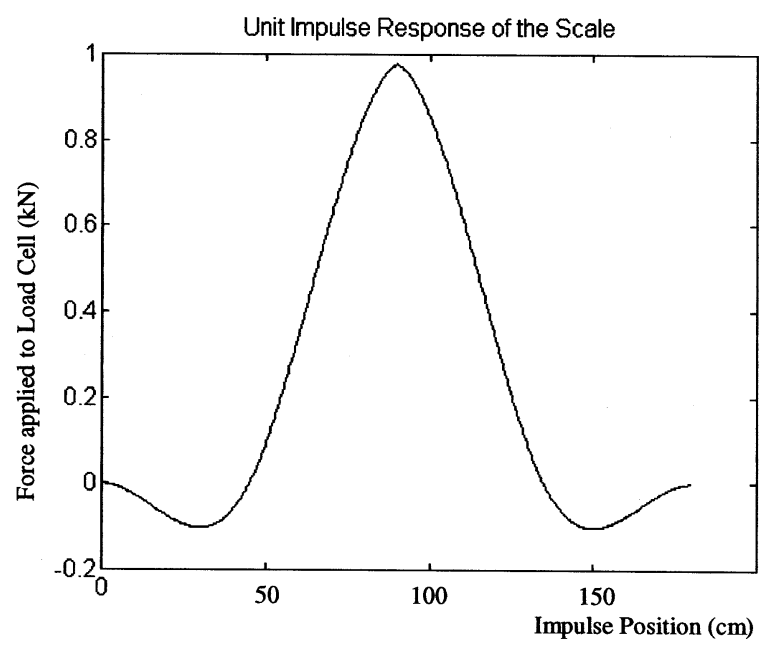

Fig. 3. Amplitude response of the belt-weighing system.

\footnotetext{
${ }^{1}$ Large in a statistical sense.
} 

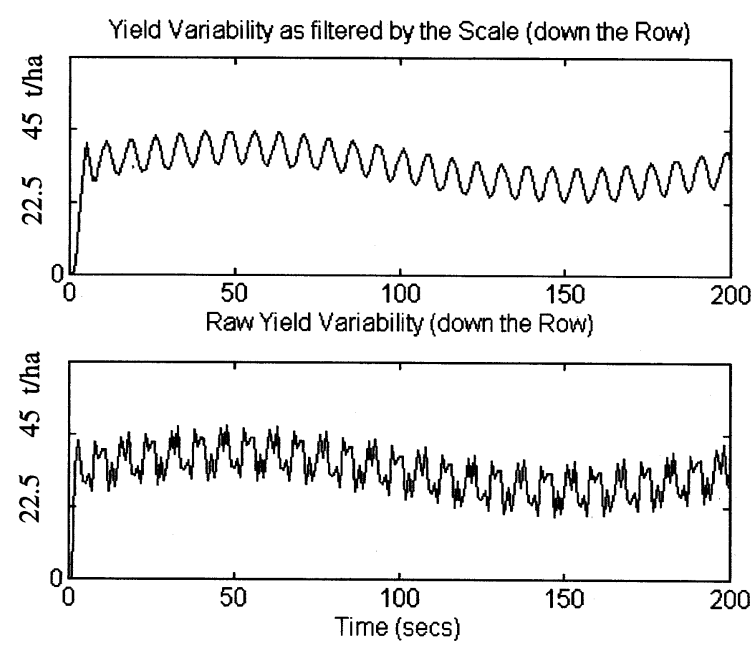

Fig. 4. The simulated response of the yield monitor to a three component $(3,9$ and $244 \mathrm{~m}$ field variability) input signal.

\subsection{Frequency response of the yield monitoring system}

Simulation studies were conducted to determine the effect of the frequency response of the belt-weighing scale along with time delays that occur when the fruit moves through the harvester. The time delay (harvester lag) occurred at two distinct locations on the harvester. The first location is at the entry point to the harvester just above the blade that frees the plant and sends it up the conveyor towards the shaker. The plants need to build up at this point to force movement of the material up the conveyor. It takes a steady stream of plants feeding into this point to push the plants on to the conveyor. This time delay is about $2 \mathrm{~s}$. The second point where the build-up occurs is just before the colour sorter. At this point the fruit moves up a conveyor inclined at $30^{\circ}$. For the fruits to climb up the incline, they need to be pushed by fruits behind them. Once again, this point leads to another 2-s delay. The last point of concern is the mixing of the fruit in the rear cross conveyor because of splitting the fruit at the vibratory shaker as explained earlier. This path difference, which is equal to the length of the rear cross conveyor, imparts a 3-s overlap between the two different routes. These delays and mixing can each be modelled by a first-order transfer function. The effect of scale transfer function and these three first-order time delays on a three-component input signal is shown in Fig. 4. The input signal consisted of a lower-frequency component corresponding to $244 \mathrm{~m}$ distance, an intermediate-frequency component corresponding to $9 \mathrm{~m}$ distance, and a higher-frequency component corresponding to $3 \mathrm{~m}$ distance. The effect of the scale along with the three first-order delays described above was to completely remove the high frequency component.

A preliminary study, with an accelerometer mounted directly on the boom elevator frame using a sampling frequency of $5 \mathrm{kHz}$ to avoid aliasing problems, 
indicated that the frequency content of the data did not exceed about $90 \mathrm{~Hz}$. Subsequent tests conducted at a sampling rate of $180 \mathrm{~Hz}$ confirmed that the maximum frequency content of the data was around $85 \mathrm{~Hz}$. All frequency studies were conducted using a discrete Fourier transform (DFT) along with a Hamming window. The DFT was implemented through a fast Fourier transform (FFT) using 2048 data points.

Based on this information, an anti-aliasing, analog, second-order, low-pass filter was designed with a corner frequency of $30 \mathrm{~Hz}$ and a stop band of $100 \mathrm{~Hz}$. Using this system the output of the load cell was measured at a sampling rate of $180 \mathrm{~Hz}$ when the harvester was running with no fruit on the belt. Fig. 5a is the spectral response of the load cell signal which shows that the high-frequency content of the signal above the corner frequency has been adequately removed by the filter. However, a close look at the low-frequency range indicated that the data contained peaks at frequencies as low as $0.3 \mathrm{~Hz}$ (Fig. 5b). To completely remove all the vibration noise a finite impulse response (FIR) digital filter was incorporated. This low-pass digital filter was set up in an eight-stage configuration to enhance software efficiency.

Fig. 6a shows the complete frequency response of the system from analog through the eight-stage digital low-pass filter. All frequency contents above $0.3 \mathrm{~Hz}$ have been reduced by at least $20 \mathrm{~dB}$ (Fig. 6b). It essentially preserved data up to 0.1 $\mathrm{Hz}$ only, which results in a spatial resolution of $27 \mathrm{~m}$. In order to obtain $10 \mathrm{~m}$ spatial resolution, which was the original intent of this study, adaptive signal processing would be necessary. In view of this new finding, we settled for a lower spatial resolution of $30 \mathrm{~m}$.

Another concern in data acquisition was to sample the load cell on the basis of fixed time or fixed travel distance along the belt. Pelletier (1998) showed that it was important to sample the signal on the basis of a fixed distance along the belt rather than time since the elevator belt speed can vary anywhere in the range of $0.5-1 \mathrm{~m} / \mathrm{s}$ depending on the fruit load (yield). A belt speed sensor (magnetic pickup) was added to the data acquisition system to achieve sampling on the basis of fixed travel distance along the belt. At the lowest belt speed of $0.5 \mathrm{~m} / \mathrm{s}$, a sampling distance of $3 \mathrm{~mm}$ along the belt would be equivalent to a sampling frequency of $167 \mathrm{~Hz}$, which is more than twice the frequency content of the load cell data after the analog filtering stage, thus avoiding aliasing problems.

\subsection{Yield monitoring system}

In this study a three-idler weigh bridge as shown in Fig. 2, along with an angle transducer, and a belt speed sensor was fabricated. Note that the weigh bridge consisted of two sets of three idlers, one on each side of the belt. These sensors were interfaced to the A/D converter through anti-aliasing filters. A 486 embedded micro-computer communicated serially with the A/D converter and a sub-meter accuracy DGPS. The microcomputer further processed the data using a series of FIR filters as described earlier and stored the processed yield data. A schematic diagram of the data acquisition and processing system is shown in Fig. 7. 


\section{Calibration and validation of the yield monitor}

The yield monitoring system was field tested after 2 weeks of continued use and once again 3 weeks later. The first test consisted of a short calibration trial followed by a validation trial. The validation trial was repeated again 3 weeks later to verify that the system was stable and still performing to specifications.

The device was tested using the University of California, Davis, instrumented bulk weigh wagon. The field trial was performed by loading the weigh wagon from
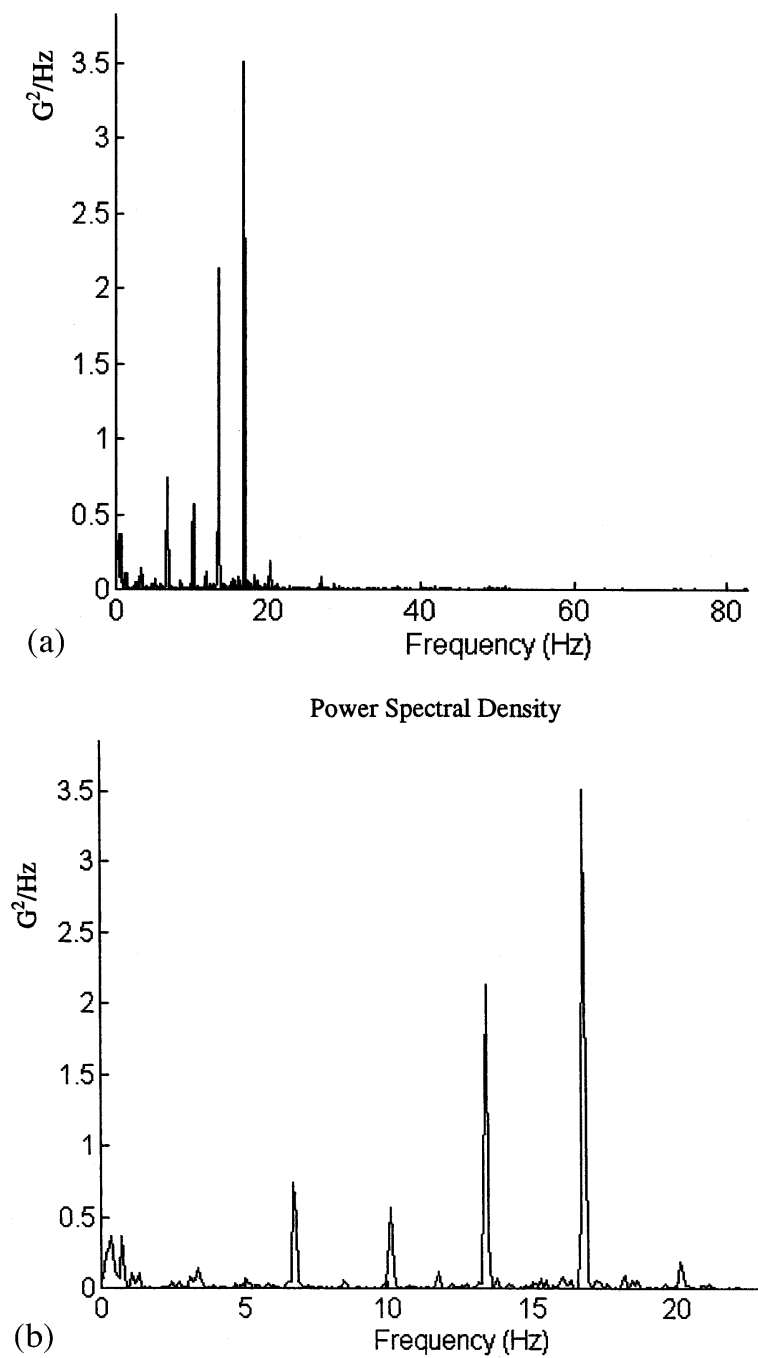

Fig. 5. (a) A DFT of the mechanical vibrations and the belt dynamics imparted directly on to the scale through the load cell. (b) The low-frequency content of the mechanical vibration and the belt dynamics imparted directly on to the load cell through the weigh idler. 

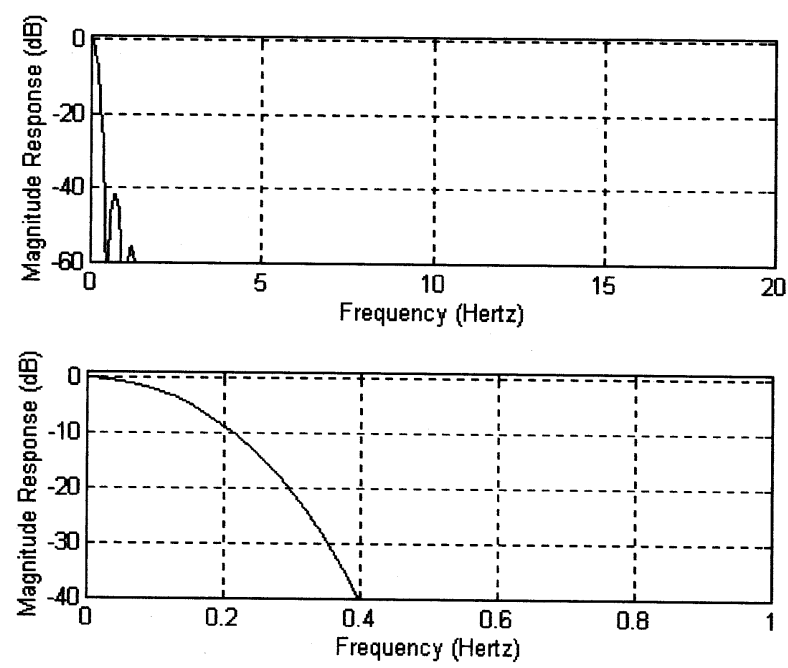

Fig. 6. The complete frequency response of the system, from the analog through to the eight-stage filter decimation low-pass filter (a) zoomed into the $0-20-\mathrm{Hz}$ frequency portion of the spectrum and (b) zoomed into the $0-1-\mathrm{Hz}$ frequency portion of the spectrum.

the tomato harvester. The tomatoes were passed across the yield monitor before being loaded into the weigh wagon. A digital read-out display on the weigh wagon provided the bulk fruit weight as tomatoes accumulated in it. The elevator loading belt was stopped periodically to read the weigh wagon bulk weight, and a corresponding mark was made on the data set for the tomato yield monitor. This was done to allow a comparison of the two measuring systems later. After the test, the two data sets were compiled and a regression was performed to measure the accuracy of the system.

\section{Results and discussion}

The first calibration set was used to establish the gain of the belt-weighing system. The tare weight of the belt-weighing system was measured by running repeated trials with an empty belt. This calibration then became the baseline for all of the following validation tests. The calibration results from this trial resulted in a slope of 0.289 and a coefficient of determination, $r^{2}=0.999$ (Fig. 8a).

Following the calibration test, a validation test was conducted the following day. The validation trial resulted in an $r^{2}=0.997$ (Fig. 8b). Another validation trial was performed 3 weeks later near end of the season. The system had remained stable with no change in the gain of the system. The accuracy achieved by the device based on the full load capacity of the weigh wagon (4500 kg) was $\pm 1.4 \%$ for the validation trial at the $95 \%$ confidence level. 
One problem noticed over the course of the season was that the front set of rollers (on the driver side of the elevator) had a tendency to build up a layer of mud. This was significant enough to reduce the accuracy of the front set of rollers. All previously stated calibrations and accuracy were reported without the use of the front set of rollers. Fortunately, the rear set of rollers was unaffected by this and never needed cleaning throughout the entire season. However, it was advisable to check them from time to time.

\subsection{Yield mapping}

This yield monitor was used to map the yield variability of tomato fields during the 1997 harvesting season by combining the DGPS data with the weight data. About ten fields operated by the Button and Turkovich ranch, Winters, CA, were mapped for the processing tomato yield during the 1997 harvesting season. The yield monitor data were smoothed using a low-pass filter and then interpolated using an inverse distance interpolation technique available in the Surfer software (Golden Software, Golden, CO 80401) to generate the yield map. Fig. 9 shows a field in which yield varied from 63 to $113 \mathrm{t} / \mathrm{ha}$ with an average yield of about 88 $\mathrm{t} /$ ha. The analysis of the yield map indicated that the lowest $20 \%$ yielding area within a field produced less than half the tomatoes compared to the highest $20 \%$ yielding area within the same field.

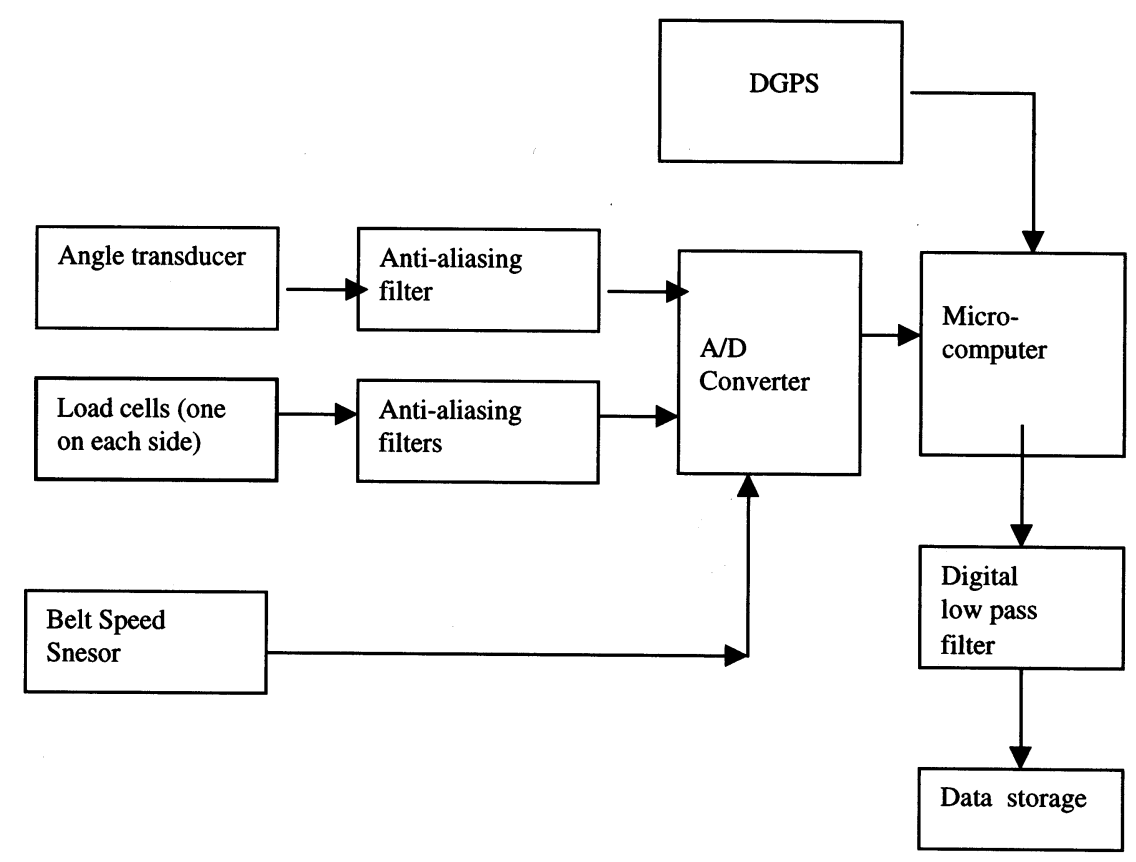

Fig. 7. A schematic diagram of the data acquisition and signal processing system. 

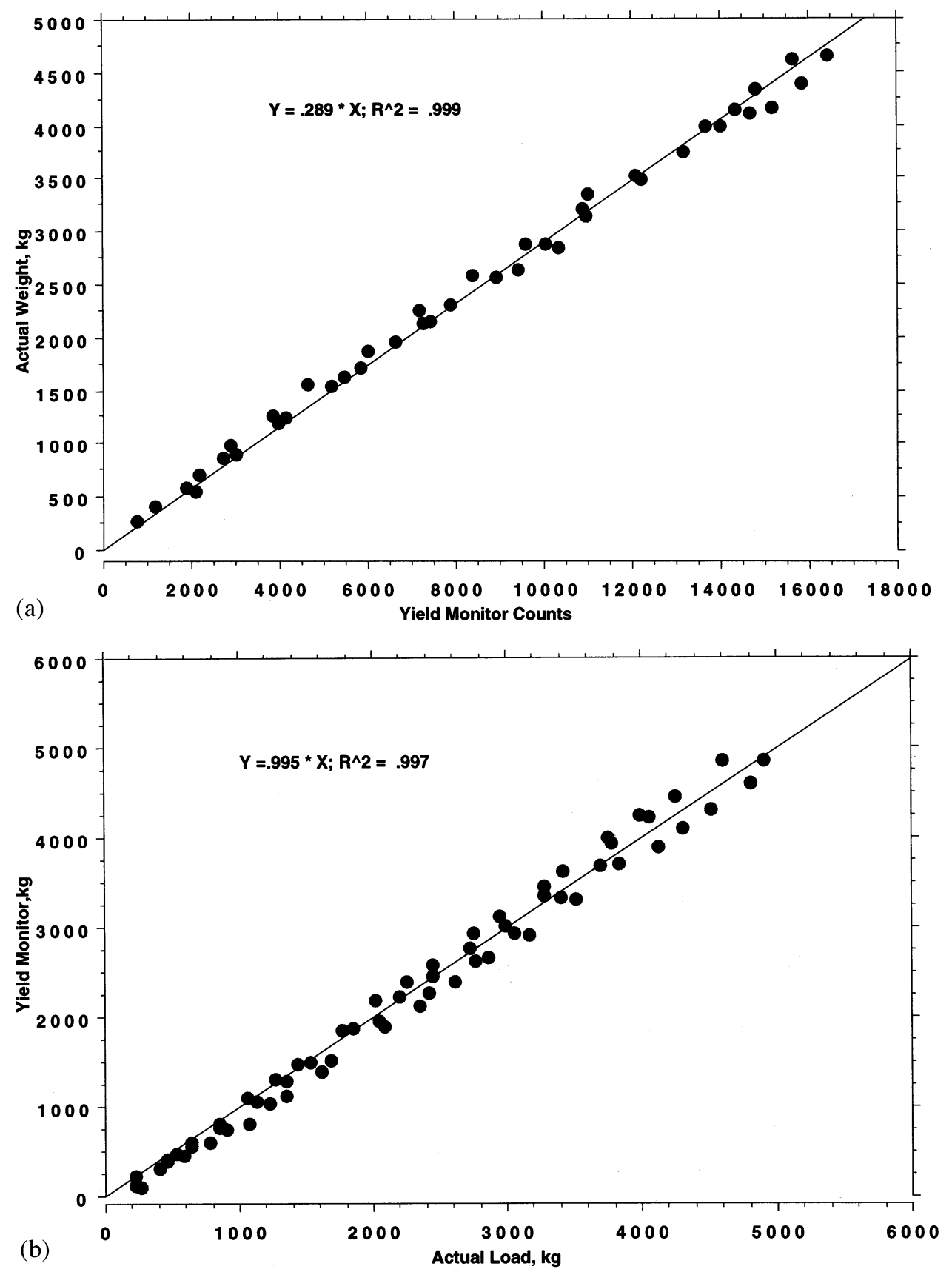

Fig. 8. (a) Calibration curve for the yield monitor which was obtained using a weigh wagon. (b) Response of the yield monitor during the first validation trial. 


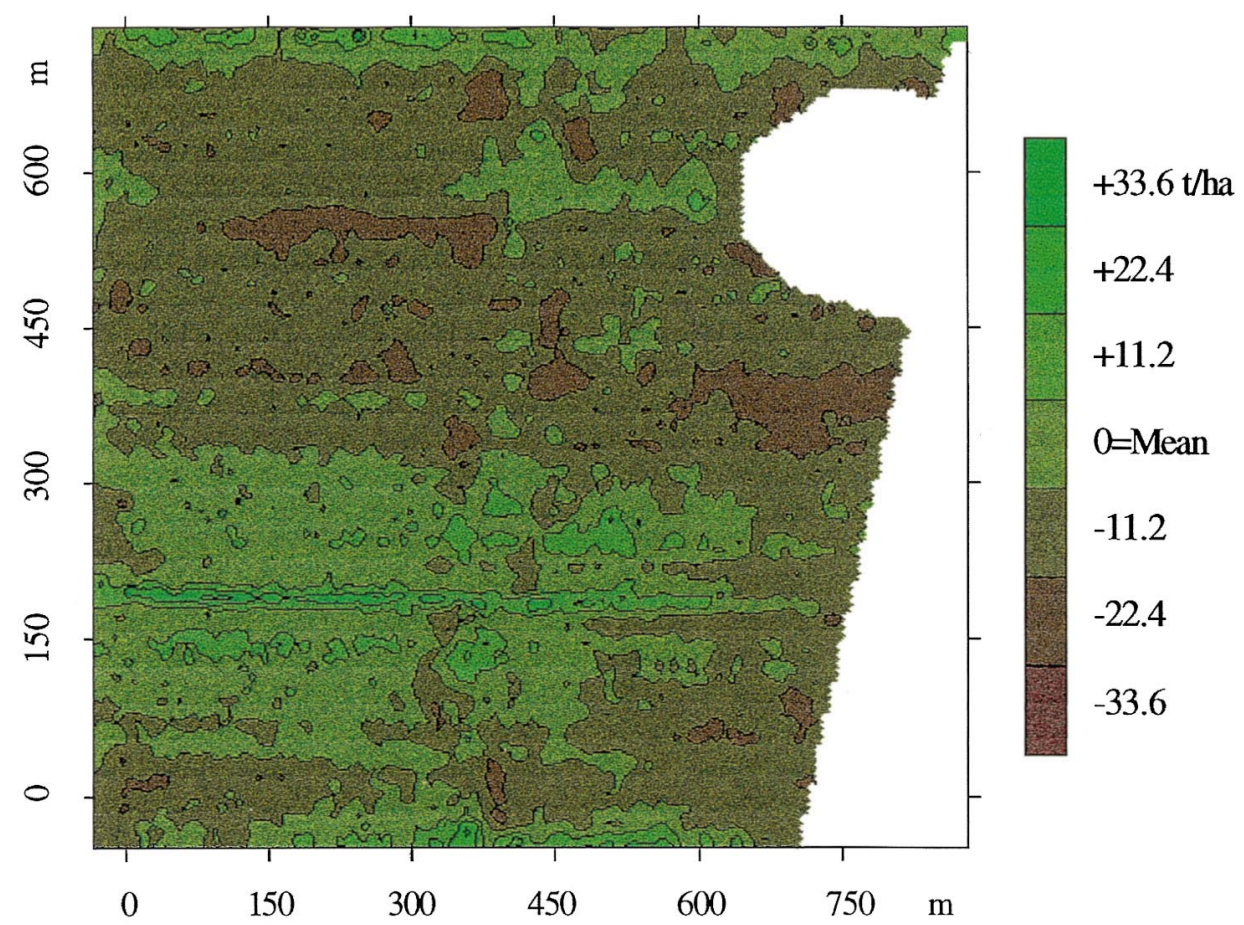

Fig. 9. A yield map obtained using the tomato yield monitor. The map shows deviation from the mean yield of $88 \mathrm{t} / \mathrm{ha}$.

\subsection{Monitoring truck load}

As explained earlier, the truck load monitoring essentially involves integrating the load sensor output over the whole truck load without regard to the field location from where the data originated. The integration was implemented in the software. However, when the validated calibration was used to estimate truck load it resulted in an unexplained 15\% systematic error. This aspect needs further investigation.

\section{Conclusions}

On the basis of this study, we reached the following conclusions:

1. A continuous weigh-type yield monitor which consists of a three-idler weighbridge, an angle transducer, a belt speed sensor, and a DGPS along with necessary data acquisition and signal processing system was successfully developed to measure and map tomato yield.

2. The yield monitor calibration was validated at two separate times during the season: the first after 2 weeks of use during the harvest season and once more 
after three additional weeks of use. The coefficient of determination, $r^{2}$, between the yield monitor prediction and the actual fruit weight was 0.997 .

3. A typical yield map indicated considerable yield variability within a tomato field. The lowest $20 \%$ yielding area within a field produced less than half the tomatoes compared to the highest $20 \%$ yielding area within the same field.

\section{Acknowledgements}

We are grateful to the California Tomato Research Institute (CTRI) and National Research Initiative Cooperative Grants program (NRICGP), United States Department of Agriculture (USDA) for their financial support to this project.

\section{References}

Auernhammer, H., Demmel, M., Pirro, P.J.M., 1995. Yield measurement on a self propelled forage harvesters. ASAE Paper 95-1757. ASAE, St. Joseph, MI 49085.

Boydell, B., Vellidis, G., Perry, C., 1996. Dynamics of peanut flow through a peanut combine. Precision Agriculture ASA-CSSA-SSSA, pp. 805-814.

California Statistical Abstracts, 1998. Department of Finance, 39th ed., Sacramento, CA.

Campbell, R.H., Rawlins, S.L., Han, S. 1994. Monitoring methods for potato yield mapping. ASAE Paper 94-1584, ASAE, St. Joseph, MI 49085.

Colijn, H., 1983. Weighing and proportioning of bulk solids, 2nd ed. Trans Tech Publications. ISBN 0-87849-047-7.

Durrence, J.S., Perry C.D., Vellidis, G., Thomas, D.L., Kvien, C.K., 1998. Mapping peanut yield variability with an experimental load cell yield monitoring system. Proceedings of the 4th International Conference on Precision Agriculture, July 19-22, St. Paul, MN, p. 53.

Hofman, A.R., Panigrahi, S., Gregor, B., Walker, J., 1995. In: Field Monitoring of Sugarbeets. ASAE Paper 95-2114. ASAE, St. Joseph, MI 49085.

Miller, W.M., Whitney, J.D., 1998. Development of yield monitoring systems for Florida citrus. ASAE Paper 98-1098. ASAE, St. Joseph, MI 49085.

Nolan, S.C., Haverland, G.W., Goddard, T.W., Green, M., Penney, D.C., 1996. Building a yield map from geo-referenced harvest measurements. Precision Agriculture ASA-CSSA-SSSA, pp. 885-892.

Pelletier, M.G., 1998. Development of a tomato yield/load monitor. An Unpublished Ph.D. Thesis. Bio. and Agric. Eng. Dept., Univ. Cal., Davis, Davis, CA 95616.

Pierce F.J., Anderson, N.W., Colvin, T.S., Schueller, J.K., Humburg, D.S., McLaughlin, N.B., 1997. Yield mapping. The Site-Specific Management for Agricultural Systems ASA-CSSA-SSSA, pp. 211-243.

Rawlins, S.L., Campbell, G.S., Campbell, R.H., Hess, J.R., 1995. Yield mapping in Potato. In: Robert P.C. et al. (Eds.), Site-specific Management for Agricultural Systems. ASA, CSSA, and SSSA, Madison,WI, pp. 59-68.

Sudduth, K.A., Hummel, J.W., Cahn, M.D., 1991. Soil organic matter sensing: a developing science. Automated Agriculture for the 21st Century. Proceedings of the 1991 Symposium, 307 pp.

Vanischen, R., De Baerdemaeker, J., 1993. Continuous wheat yield measurement on a combine. Automated Agriculture for the 21st Century. ASAE Publ. 1191. ASAE, St. Joseph, MI 49085, 346 pp.

Wild, K., Auernhammer, H., Rottmeier, J., 1994. Automatic data acquisition on round balers. ASAE paper 94-1582. ASAE, St. Joseph, MI 49085.

Wilkerson, J.B., Kirby, J.S., Hart, W.E., Woma, A.R., 1994. Real-time cotton flow sensor. ASAE Paper 94-1054. ASAE, St. Joseph, MI 49085. 